\title{
Anticoagulant Properties of a New Anticoagulant Diethyl Citrate in Rabbit Model
}

\author{
Jin HAN ${ }^{1}$, Zeng-ying LIU², Chen-ying RAO², Jian-ming OUYANG ${ }^{2, b}$, \\ Da GUO ${ }^{2}$, and Bao-song GU1 ${ }^{1, a, *}$ \\ ${ }^{1}$ Department of Nephrology, the Second Hospital of Xi'an Jiaotong University, Xi'an \\ 710004, China \\ ${ }^{2}$ Institute of Biomineralization and Lithiasis Research, Jinan University, Guangzhou \\ 510632, China \\ aguibsdoctor@sina.com, btoyjm@jnu.edu.cn \\ ${ }^{*}$ Corresponding author
}

Keywords: Diethyl citrate, Anticoagulant, Hemodialysis

\begin{abstract}
A novel anticoagulant, diethyl citrate $\left(\mathrm{Et}_{2} \mathrm{Cit}\right)$ was synthesized and characterized by carbon nuclear magnetic resonance $\left({ }^{13} \mathrm{C} \mathrm{NMR}\right)$, mass spectrometry and UV-visible spectroscopy. There were two isomers with different chemical environments, that is, 1, 3-diethyl citrate and 1,5-diethyl citrate. Through the determination of whole blood activated clotting time (ACT), the anticoagulant effect in vitro of $\mathrm{Et}_{2} \mathrm{Cit}$ was investigated. $\mathrm{Et}_{2} \mathrm{Cit}$ can reduce ions calcium concentration in blood then to play the role of anticoagulation. $\mathrm{Et}_{2} \mathrm{Cit}$ was superior to anticoagulant $\mathrm{Na}_{3} \mathrm{Cit}$ duing to the steric hindrance of two ethyl groups in citric acid, which leading a decrease of chelated ability compared to that of $\mathrm{Na}_{3} \mathrm{Cit}$. It can prevent hypocalcemia when $\mathrm{Et}_{2} \mathrm{Cit}$ as anticoagulation, due to the ion blood calcium concentration resumed faster than $\mathrm{Na}_{3} \mathrm{Cit}$. Consequently $\mathrm{Et}_{2} \mathrm{Cit}$ may be a potential ideal anticoagulant.
\end{abstract}

\section{Introduction}

Anticoagulation is the important guarantee which the hemodialysis carries on smoothly. When sodium citrate $\left(\mathrm{Na}_{3} \mathrm{Cit}\right)$ was used as anticoagulant, because the chelated ability between $\mathrm{Na}_{3} \mathrm{Cit}$ and $\mathrm{Ca}^{2+}$ ions is much strong, it is much slow for the chelated compound to release its $\mathrm{Ca}^{2+}$ ion, thus the low calcium blood sickness was led.

Excessive heparin treatment during dialysis inhibits platelet aggregation, which enhances bleeding tendency with a secondary hemorrhage incidence as high as 10\%-30\%. In addition, it causes several other side effects, such as osteoporosis. Therefore, how to choose appropriate anticoagulant(s) for blood purification therapy is one of the major clinical problems. Low molecular heparin has high cost and bleeding risk [1].

However, all these methods exhibit limitations [1-4]. For example, low molecular heparin has high cost and bleeding risk; no heparin dialysis needs high blood flow, which can cause blood coagulation in dialyser and blood vessel, resulting in dialysis failure; low doses heparin dialysis requires a blood flow rate of over $180 \mathrm{~mL} / \mathrm{min}$, and the incidence of secondary hemorrhage is about 13\%; when using protamine to neutralize heparin, it is very hard to accurately adjust the protamine/heparin ratio, and the intravenous application of protamine may cause low blood pressure, allergy and even ventricular fibrillation [5]; prostacyclin interferes hemodynamics and can lead to severe hypotension; the resource of recombinant hirudin reagents is limited. 
Therefore, when $\mathrm{Et}_{2} \mathrm{Cit}$ or $\mathrm{Na}_{3} \mathrm{Cit}$ was used as an anticoagulation, the $\mathrm{pH}$ increase of dialysate, that is, dialysis in alkaline conditions, could not only achieve the purpose of anticoagulant, but also avoid the occurrence of dialysis acidosis, which would improve the survival rate and quality of life.

\section{Materials and Methods}

\section{Reagents and Apparatus}

Diethyl citrate $\left(\mathrm{Et}_{2} \mathrm{Cit}\right)$ was synthesized in our laboratory. It was analyzed by elemental analysis, infrared spectroscopy, mass spectrometric analysis and nuclear magnetic resonance. The purity was determined by thin layer chromatography and acid titration. The mass fraction of $\mathrm{Et}_{2} \mathrm{Cit}$ was $99.27 \%$. Other chemical reagents were analytical grade and purchased from Guangzhou chemical reagent company (Guangzhou, China). Experimental water is re-distilled water.

Bruker AM 500 NMR instrument (with $\mathrm{CDCl}_{3}$ as solvent and TMS as internal standard).

\section{Anticoagulant Test in Vitro -activated Coagulation Time (ACT) Test}

The efficacy of in vitro anticoagulation for $\mathrm{Et}_{2} \mathrm{Cit}$ was investigated by measuring ACT. The methods in details are as follows: $12 \mathrm{mg}$ commercial silica was pre-warmed in a $1-\mathrm{cm}$ diameter glass test tube in $37^{\circ} \mathrm{C}$ water bath, and then $1.8 \mathrm{ml}$ venous blood from the experimental rabbits, together with $0.2 \mathrm{~mL}$ of different concentrations of anticoagulant (Table 1), was added immediately after extraction. After supplementing anticoagulant, the test tube was quickly plugged with a rubber plug and the solution was mixed upside down for three times. The tube was put into $37^{\circ} \mathrm{C}$ water bath and timing started. After $60 \mathrm{~s}$, the blood clotting was monitored every $5 \mathrm{~s}$ by tilting the tube. The time when the first blood $\operatorname{clot}(\mathrm{s})$ appeared was recorded as ACT. The test was parallelly determined 3 times, and an average value was used.

Twenty whole blood samples from selected experimental rabbits were divided into four groups, each group using the following anticoagulant:

Group I was the negative control group: $0.1 \mathrm{~mL} 0.9 \%$ physiological saline;

Group II was the positive control group: $0.1 \mathrm{~mL} 4 \%$ sodium citrate solution;

Group III was experimental group 1: $0.1 \mathrm{~mL} \mathrm{4 \%} \mathrm{Et}_{2}$ Cit solution;

Group IV was experimental group 2: $0.1 \mathrm{~mL} \mathrm{4 \%} \mathrm{triethyl} \mathrm{citrate} \mathrm{solution.}$

Effect of $\mathrm{Et}_{2} \mathrm{Cit}$ concentration: 36 whole blood samples were divided into nine groups, each group using the concentration of $\mathrm{Et}_{2} \mathrm{Cit}$ as shown in Table 2. That is, the final concentrations of $\mathrm{Et}_{2} \mathrm{Cit}$ in the blood were 0, 109, 218, 436, 545, 654, 763, 872, and $1090 \mathrm{mmol} / \mathrm{L}$, respectively.

\section{Animal Experiments}

Ten rabbits were divided into sub-experiments and anesthetized with $1 \%$ pentobarbital into the ear vein before the experiments. The anesthetic did not exceed $1 \mathrm{~mL} / \mathrm{kg}$. Three milliliters of arterial blood was extracted from the carotid artery of the rabbits, after which $1 \mathrm{~mL}$ of the arterial blood after centrifugation was used to measure baseline blood calcium values. The remaining $2 \mathrm{~mL}$ of blood was used to measure the free $\mathrm{Ca}^{2+}$ in blood after it was mixed with $3.2 \% \mathrm{Na}_{3} \mathrm{Cit}$ or $33.5 \% \mathrm{Et}_{2} \mathrm{Cit}$ at a blood/ coagulant ratio of 9:1. A venous cannulation was performed on the unilateral femoral vein of the rabbits to establish the tunnel for drug-giving. The method in detail was: exposed the femoral vein fully, then inserting a venous cannula at $1.5 \mathrm{~cm}$ above the ligation point at 
the distal end of the vein. After the venous cannulation was successfully finished a small amount of saline was added to seal the tube in order to avoid blood coagulation in the tube. An arterial cannulation was performed on the neck of the rabbits to establish the tunnel for blood samples collection. After the arterial cannulationn was successfully finished, a small amount of saline was also added to seal the tube in order to avoid blood coagulation in the tube.

\section{Results And Discussion}

\section{${ }^{13} \mathrm{C}$ NMR Spectrum Analyses of $\mathrm{Et}_{2} \mathrm{Cit}$}

Figure 1a showed the ${ }^{13} \mathrm{C}$ NMR spectra of $\mathrm{Et}_{2} \mathrm{Cit}$, and the theoretical spectra of the two isomers of $\mathrm{Et}_{2} \mathrm{Cit}$ were also showed in Figures $1 \mathrm{~b}$ and $1 \mathrm{c}$. From these ${ }^{13} \mathrm{C}$ NMR spectra we can determine that the synthesized product is a mixture of two isomers, that is the 1,5-diethyl citrate and 1,3-diethyl citrate (Figures 1d and 1e). The two kinds of esters have different chemical environments. However, the proportion between them is still difficult to be judged.

The mass spectrometry (MS) of $\mathrm{Et}_{2} \mathrm{Cit}$ was measured and the molecular fragment peaks of the two isomers of $\mathrm{Et}_{2} \mathrm{Cit}$ were shown in Table 1.

The UV-visible spectrum of $\mathrm{Et}_{2} \mathrm{Cit}$ in aqueous solution was showed in Figure 2. The main absorption peak was located at $220 \mathrm{~nm}$.

Based on the results of mass spectrometry and NMR, it can be concluded that the synthesized product is the target product $\mathrm{Et}_{2} \mathrm{Cit}$.

\section{Whole Blood Activated Clotting Time (ACT) Test}

Figure 3 showed the whole blood activated clotting time (ACT) in the presence of various anticoagulants when the rabbit venous blood was used. Twenty rabbit blood samples were divided into four groups, each containing five. The ACT for $\mathrm{Et}_{2} \mathrm{Cit}_{\text {group }}$ was $980 \pm 66 \mathrm{~s}$, which was significantly higher than the controls group (136 $\pm 22 \mathrm{~s})$ and triethyl citrate group $(256 \pm 42 \mathrm{~s})$, but significantly lower than the $\mathrm{Na}_{3} \mathrm{Cit}$ group, the blood of which has not coagulated within 4 hour, that is $14400 \mathrm{~s}$. This suggests that the chelate ability of $\mathrm{Et}_{2} \mathrm{Cit}$ is weaker than $\mathrm{Na}_{3} \mathrm{Cit}$, but stronger than triethyl citrate. Consequently $\mathrm{Et}_{2} \mathrm{Cit}$ may be a potential ideal anticoagulant due to good anticoagulation and rapidly dissociating calcium. The experimental data was analyzed by inter-group $t$ test. The ACT of group III was evidently longer than group I, with statistically significant difference $\left(\mathrm{P}_{1}<0.01\right)$. The ACT of group IV was also longer than group I, with statistically significant difference $\left(\mathrm{P}_{2}<0.01\right)$. The ACT of group III was remarkably longer than group IV, with statistically significant difference $\left(\mathrm{P}_{4}<0.01\right)$.

That is, $\mathrm{Et}_{2} \mathrm{Cit}$ not only has anticoagulant function, but also speed of resolving rapidly than calcium nutrium. It overcome low calcium blood disease problem in calcium nutrium anticoagulant, can not cause alkalosis of high sodium, the load question of the capacity does not exist, and can not cause high calcium blood disease because of injecting too much calcium. Diethyl citrate is simpler than citrate nutrium. It might lighten patient's agony and mental burden; lighten the nurse's work load.

$\mathrm{Et}_{2} \mathrm{Cit}$ was superior to anticoagulant $\mathrm{Na}_{3} \mathrm{Cit}$ duing to the introduction of two ethyl groups in citric acid, which leading an increase of the steric hindrance resistance when $\mathrm{Et}_{2} \mathrm{Cit}$ chelating with $\mathrm{Ca}^{2+}$ ion and leading a decrease of chelated ability compared to that of $\mathrm{Na}_{3} \mathrm{Cit}$, thus increasing the dissociation speed of $\mathrm{Ca}^{2+}$ ion from the chelate. It can 
overcome the hypocalcemia and other problems those when $\mathrm{Na}_{3} \mathrm{Cit}$ was used as anticoagulation. Consequently $\mathrm{Et}_{2} \mathrm{Cit}$ may be a potential ideal anticoagulant.

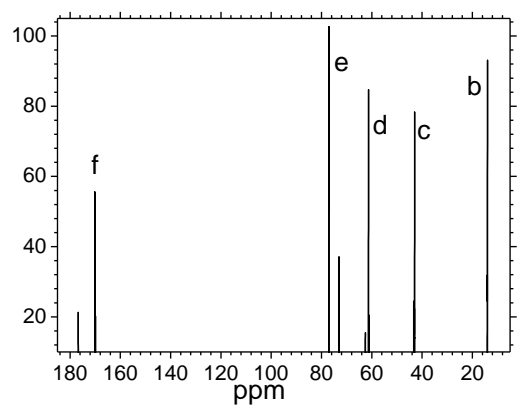

(a)

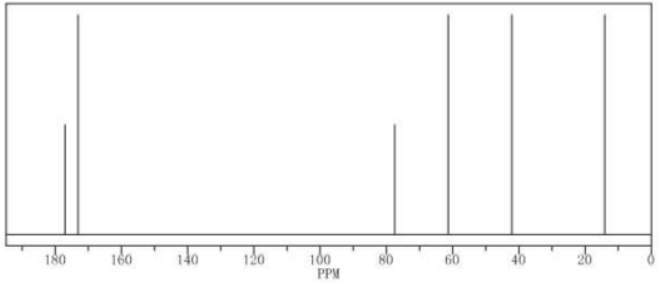

(b)<smiles>CCOC(=O)CC(O)(CC(=O)OCC)C(=O)O</smiles>

(d)

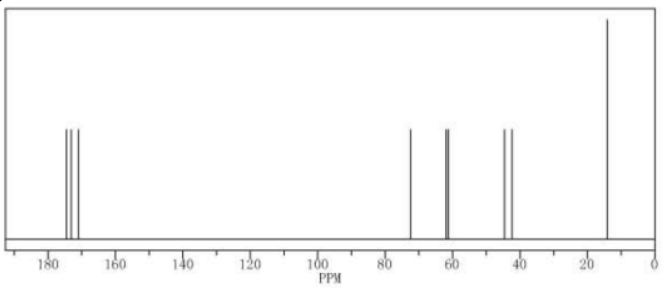

(c)<smiles>CCOC(=O)CC(O)(CC(=O)O)C(=O)OCC</smiles>

(e)

Figure $1 .{ }^{13} \mathrm{C}$ NMR spectra of diethyl citrate and its isomers. (a) Whole spectrum of ${ }^{13} \mathrm{C}$ NMR; (b) theoretical spectrum of isomer 1,5-diethyl citrate; (c) theoretical spectrum of isomer 1,3-diethyl citrate; (d) molecular structure of 1,5-diethyl citrate; (e) molecular structure of 1,3-diethyl citrate.

Table 1 Fragment peaks for two diethyl citrate isomers. (a) 1,3-diethyl citrate; (b) 1,5-diethyl citrate

\begin{tabular}{ll}
\hline (a) 1,3-diethyl citrate & (b) 1,5 -diethyl citrate \\
\hline$m / z 203\left[\mathrm{M}-\mathrm{OCH}_{2} \mathrm{CH}_{3}\right]^{+}$ & $m / z 203\left[\mathrm{M}-\mathrm{OCH}_{2} \mathrm{CH}_{3}\right]^{+}$ \\
$m / z 185\left[\mathrm{M}-\mathrm{OCH}_{2} \mathrm{CH}_{3}-\mathrm{OH}\right]^{+}$ & $m / z 158\left[\mathrm{M}-2 \mathrm{OCH}_{2} \mathrm{CH}_{3}\right]^{2+}$ \\
$m / z 156\left[\mathrm{M}-\mathrm{OCH}_{2} \mathrm{CH}_{3}-\mathrm{OH}-\mathrm{CH}_{2} \mathrm{CH}_{3}\right]^{2+}$ & $m / z 141\left[\mathrm{M}-2 \mathrm{OCH}_{2} \mathrm{CH}_{3}-\mathrm{OH}\right]^{2+}$ \\
$m / z 114\left[\mathrm{M}-\mathrm{OCH}_{2} \mathrm{CH}_{3}-\mathrm{OH}-\mathrm{CH}_{2} \mathrm{CH}_{3}-\mathrm{CH}_{2} \mathrm{CO}\right]^{+}$ & $m / z 116\left[\mathrm{M}-2 \mathrm{OCH}_{2} \mathrm{CH}_{3}-\mathrm{CH}_{2} \mathrm{CO}\right]^{+}$ \\
$m / z 70\left[\mathrm{M}-\mathrm{OCH}_{2} \mathrm{CH}_{3}-\mathrm{OH}-\mathrm{CH}_{2} \mathrm{CH}_{3}-\mathrm{CH}_{2} \mathrm{CO}-\mathrm{COO}\right]^{+}$ & $m / z 74\left[\mathrm{M}-2 \mathrm{OCH}_{2} \mathrm{CH}_{3}-2 \mathrm{CH}_{2} \mathrm{CO}\right]^{+}$ \\
\hline
\end{tabular}




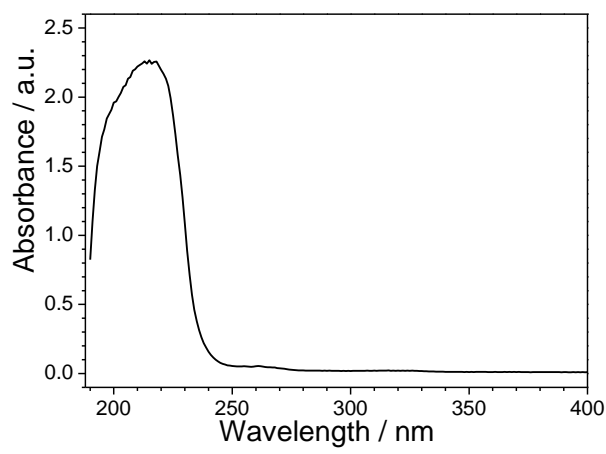

Figure 2. UV-visible spectrum of $\mathrm{Et}_{2} \mathrm{Cit}$ in aqueous solution.

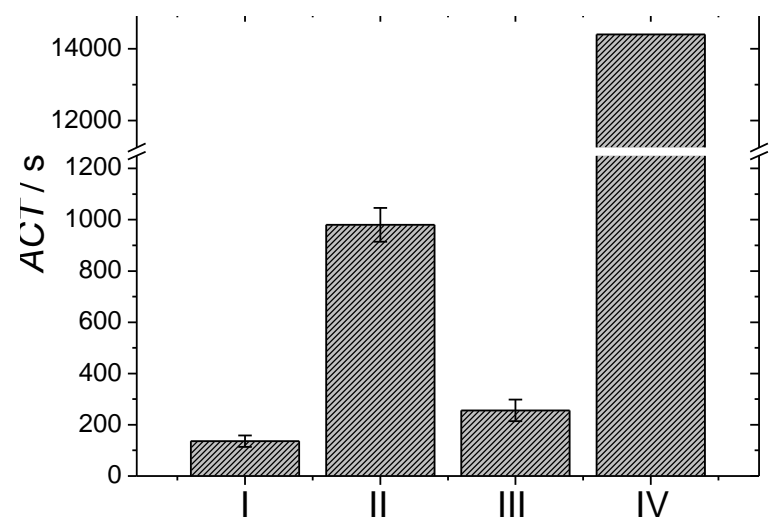

Figure 3. Activation coagulation time (ACT) of rabbit whole blood samples. Group I: Control group; Group II: $\mathrm{Na}_{3} \mathrm{Cit}$; Group III: $\mathrm{Et}_{2} \mathrm{Cit}$; Group IV: triethyl citrate. Take experiments with the rabbit vein blood preparation as the object, when the use different anticoagulant obtains whole blood activation coagulation time (ACT)

\section{Animal Experiments}

The anticoagulant effect of $\mathrm{Na}_{3} \mathrm{Cit}$ and new anticoagulants $\mathrm{Et}_{2} \mathrm{Cit}$ through vivo experiments of rabbit was investigated. The calcium concentration of rabbits was less than $40 \%$ of the based blood calcium in 0.5 min after $33.5 \% \mathrm{Et}_{2} \mathrm{Cit}_{\text {it }}$ was injected into the rabbits, indicating there was anticoagulant effect. But the blood calcium levels were quickly restored to more than $60 \%$ of based blood calcium in $1 \mathrm{~min}$, indicating the anticoagulant effect was disappeared in $1 \mathrm{~min}$ after injection, and there was no possibility to cause hypocalcemia at the same time. In contrast, the anticoagulant effect was disappeared after $3.2 \% \mathrm{Na}_{3}$ cit was injected into rabbits for $3 \mathrm{~min}$, the possibility of causing hypocalcemia had reduced after $7 \mathrm{~min}$. It showed the releasing $\mathrm{Ca}^{2+}$ rate of $\mathrm{CaEt}_{2} \mathrm{Cit}$ was faster than that of CaCit, and the possibility of hypocalcemia caused by $\mathrm{Et}_{2} \mathrm{Cit}$ anticoagulant had reduced.

Naturally, human-testing is essential both scientifically and ethically. In the future, human tests are required to demonstrate whether or not $\mathrm{Et}_{2} \mathrm{Cit}$ is an ideal anticoagulant.

\section{Conclusions}

A new anticoagulant, diethyl citrate $\left(\mathrm{Et}_{2} \mathrm{Cit}\right)$, was synthesized and characterized by carbon nuclear magnetic resonance $\left({ }^{13} \mathrm{C} \mathrm{NMR}\right)$, mass spectrometry and UV-visible spectroscopy. $\mathrm{Et}_{2} \mathrm{Cit}$ not only has anticoagulant function by reducing ions calcium 
concentration of blood, but also its anticoagulant effect was superior to tradional anticoagulant $\mathrm{Na}_{3} \mathrm{Cit}$ duing to the steric hindrance of two ethyl groups in $\mathrm{Et}_{2} \mathrm{Cit}$. Animal experiments showed that $\mathrm{Et}_{2} \mathrm{Cit}$ might overcome low calcium blood disease problem in anticoagulation. Consequently $\mathrm{Et}_{2} \mathrm{Cit}$ may be a potential ideal anticoagulant

\section{Acknowledgement}

This research was supported by the National Science Foundation (NO. 81570673).

\section{References}

[1] Y.-M. Zheng, W.-L.Chen, Low molecular heparin used in hemodialysis patients with clinical observation, Clinical Emergency Medicine (Chinese) 10(2009) 268-270.

[2] B. L.Lobo, Use of newer anticoagulants in patients with chronic kidney disease, Am. J. Health-Syst. Pharm. 64 (2007) 2017-2026.

[3] Q. Tang, L.-M. Zhang, B.-B. Zou, H. Yu, Y.-L. He, Local citric acid in vitro anticoagulant, low molecular weight heparin and no heparin in high-risk hemodialysis patients with bleeding tendency of the efficacy and safety. Shanghai Medical (Chinese), 2007, 30 (12): 898-901.

[4] B.-S. Gui, G.-B. Zhao, Y. Zan, X.-Q. Ma, L. Zhao, X.-H. Wei, Study on solute clearance effect of the new anticoagulation hemodialysate of citrate, Chinese Journal of Practical Internal Medicine (Chinese), 25 (2005) 328-330.

[5] L.-C. Chang, H.-F. Lee, M.-J. Chung, V.-C. Yang, PEG-modified protamine with improved pharmacological/ pharmaceutical properties as a potential protamine substitute synthesis and in vitro evaluation, Bioconj. Chem. 16 (2005) 147-155. 